\title{
Editorial \\ Imagining the future of Latino Studies
}

Latino Studies (2013) 11, 269-270. doi:10.1057/lst.2013.27

It is clear that the field of Latino Studies has been growing and changing in myriad ways since its inception. We are now 13 years into the twenty-first century and as scholars/activists of this community some of us may take time to reflect on the direction in which our field is moving. Oftentimes, global and/or nation events such as elections, resistance movements and debates over key political issues such as immigration reform, educational access, and affordable and equitable health care galvanize our research interests and occupy our discourse. Therefore, we may well wonder, what will Latino Studies look like as we advance into the twenty-first century? One place to engage with this critical question will be at the international Latina/o Studies conference to be held in Chicago next summer (17-19 July 2014). This multidisciplinary conference is organized to consider the history and future directions of the field of Latino Studies. A group of scholars based in the Midwest have been meeting for over a year to plan the conference. The planning committee is securing multiple sponsorships from universities and Latino/a Studies Programs across the United States and assembling a national program committee to vet the proposals and organize the conference program.

The conference will consider such questions as: Do we still need to validate the field? How is current research expanding upon previous studies of Latino communities? How are the perceptions and approaches of the current wave of Latino Studies scholars, trained in the context of the emerging field of Latino Studies, different from that of previous waves of scholars who were trained in traditional disciplines or interdisciplinary perspectives such as Chicano/a Studies or Puerto Rican Studies? How does Latino Studies complement these ethnicitybased approaches? Does the research that scholars undertake impact policy decisions? How can we more effectively respond to crucial policy questions as they unfold? What are the best strategies to collectively respond to racist and discriminatory practices aimed at Latinos and other marginalized communities? How do artists and musicians shape the Latino Studies project?

A central goal of the gathering is to launch an international Latino/a Studies Association. While bodies that bring together Latino Studies scholars do exist, we do not yet have a professional organization dedicated to the field of Latino 
1 See Harvard Law Review Volume 14 (2011) for a series of articles that explore the rationale behind the creation of a Latina/o Academy of Arts and Sciences.

2 The IUPLR website (http://iuplr.nd .edu/) provides a history of the consortium and a description of its various projects.
Studies and open to all scholars and students. The Association would complement other important initiatives that are advancing the interests of Latino Studies research. For example, in 2008, scholars developed a proposal for the founding of The Latina/o Academy of Arts and Sciences and organized a conference to discuss the idea of creating an institution that would work to communicate the relevance of our research to public debates and policies around social justice issues faced by Latinos. ${ }^{1}$ Also, the Inter-University Program for Latino Research (IUPLR), established in 1983 and currently housed in Chicago at UIC, is a consortium of university based research centers that promotes and disseminates research on Latinos. ${ }^{2}$ Additionally, although Latino Studies sections are now a part of many professional and academic associations, a national space where Latino Studies scholars can meet regularly and dialogue across ethnicities, as well as across disciplinary and methodological borders still does not exist. An international Latino/a Studies Association seeks to address these needs and the conference will be an excellent venue to collectively develop the scope, mission and form of this new organization.

I encourage you to submit a proposal or panel to the conference and take part in this historic venture. Especially welcomed are papers and panels from scholars, activists, policymakers and artists who address the topic of Latino Studies from the perspective of multiple as well as intersecting disciplines, research areas and professional fields, including fields in the humanities and the social sciences as well as legal or policy analysis, medical/health practice, education, business, journalism and social work. Please share the call for papers (at the end of this issue) with your friends and colleagues and I hope to see you in Chicago in July 2014 ! 